\title{
O Contributo da Genómica do SARS-CoV-2 Para a Gestão da Pandemia de COVID-19 em Portugal
}

\section{The Contribution of SARS-CoV-2 Genomics to the Handling of the COVID-19 Pandemic in Portugal}

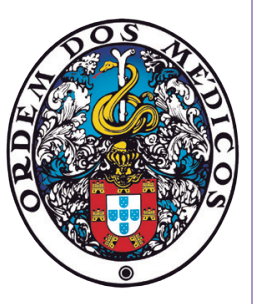

João Paulo GOMES $\square^{1}$

Acta Med Port 2021 Jul-Aug;34(7-8):493-494 - https://doi.org/10.20344/amp.16505

Palavras-chave: COVID-19; Genómica; Portugal; SARS-CoV-2

Keywords: COVID-19; Genomics; Portugal; SARS-CoV-2

A COVID-19, com mais de 150 milhões de casos confirmados e mais de três milhões de mortes $^{1}$ à data deste editorial, está a ser fortemente caracterizada pela utilização, sem precedentes na história da ciência, dos dados genéticos do agente infecioso (SARS-CoV-2) como uma importante ferramenta de monitorização da pandemia. De facto, após a sequenciação do primeiro genoma do SARS-CoV-2 de um doente de Wuhan, ${ }^{2}$ a comunidade científica empenhou-se fortemente no estudo da variabilidade genética deste vírus através da criação de consórcios de sequenciação em múltiplos países, apesar da heterogeneidade notória em termos de empenho das entidades de financiamento governamentais. A título de exemplo refira-se a atribuição, logo nos primeiros meses de pandemia, de mais de 20 milhões de libras pelo Reino Unido e de 1,8 milhões de euros por Espanha para a vigilância genética por sequenciação, contrastando com a situação de Portugal, onde não existiu, até ao presente, qualquer programa de financiamento. O esforço massivo de sequenciação por parte da comunidade científica resultou já na disponibilidade de mais de um milhão de genomas (https://www.gisaid.org/), de acesso livre às várias vertentes de investigação.

Em Portugal, a implementação da caracterização genética do SARS-CoV-2 por sequenciação foi feita no Instituto Nacional de Saúde Doutor Ricardo Jorge (INSA) e decorreu mesmo antes da identificação dos primeiros casos de COVID-19 no início de março. Foi criada imediatamente uma extensa rede laboratorial, envolvendo o sector público, privado e alguns laboratórios implementados na Academia, para a recolha de amostras com representatividade geográfica e cronológica de forma a garantir uma vigilância genética robusta. O consórcio de sequenciação, coordenado pelo INSA e contando desde o início com a colaboração do Instituto Gulbenkian de Ciência, incluiu também, muito recentemente, outros nós do consórcio GenomePT. Este trabalho conjunto permitiu já a sequenciação de mais de oito mil SARS-CoV-2, sendo que todos os resultados são disponibilizados em tempo real num site público bilingue criado para o efeito (https://insaflu.insa.pt/covid19/). Este site inclui também relatórios periódicos de situação, os quais são dirigidos não só à comunidade científica, como também às entidades de saúde pública. $\mathrm{O}$ trabalho desenvolvido pelo consórcio de sequenciação no âmbito da caracterização genética do SARS-CoV-2 veio criar como que a 'prova de conceito' relativamente à possibilidade de ter uma infraestrutura funcional e competente para apoiar a saúde pública na vigilância genética dos agentes infeciosos. De facto, a rapidez com que este consórcio procedeu à implementação e otimização de protocolos laboratoriais bem como ultrapassou questões logísticas e burocráticas, vem demonstrar que Portugal tem já capacidade instalada em termos de sequenciação para que a Epidemiologia entre definitivamente numa nova era. É de realçar que, até à data, o serviço público de toda a vigilância genética ao longo da pandemia foi realizado com verbas de cada instituição do consórcio, nunca tendo havido qualquer programa de financiamento adequado às necessidades do país.

Os objetivos da vigilância genética são semelhantes em qualquer parte do mundo, indo muito além do melhor conhecimento do agente infecioso e tendo como finalidade o apoio às entidades de saúde para controlo da pandemia. Entre eles, salientam-se: i) a determinação dos perfis mutacionais do SARS-CoV-2 para identificação e monitorização de cadeias de transmissão, bem como identificação de novas introduções do vírus no país; ii) a avaliação da transmissão na comunidade, permitindo aferir o impacto das medidas de contenção; iii) determinação do grau de variabilidade genética de antigénios ou alvos de fármacos antivirais com possível impacto no desenvolvimento / eficiência de medidas profiláticas (vacinas) e terapêuticas; iv) a avaliação de potenciais casos de reinfeção e de falência vacinal; e v) determinação de possíveis associações entre perfis genéticos (mutacionais) do SARS-CoV-2 e determinadas manifestações clínicas (ex. diferentes graus severidade da COVID-19). Embora o último objetivo seja unanimemente considerado como o mais difícil de atingir dado essencialmente as questões éticas (Regulamento Geral de Proteção de Dados - RGPD) que acarreta, os

\footnotetext{
1. Departamento de Doenças Infeciosas. Instituto Nacional de Saúde Doutor Ricardo Jorge. Lisboa. Portugal.

$\triangle$ Autor correspondente: João Paulo Gomes. J.Paulo.Gomes@insa.min-saude.pt

Recebido: 04 de maio de 2021 - Aceite: 04 de maio de 2021 - First published: 04 de junho de 2021 - Online issue published: 01 de julho de 2021 Copyright $\odot$ Ordem dos Médicos 2021
} 
mais associados às questões de saúde pública têm sido atingidos com um sucesso notável. Exemplo disso foi a identificação da introdução de uma variante genética em Portugal umas semanas antes dos primeiros casos confirmados a 2 de março 2020, a qual se disseminou massivamente pelo Norte e Centro e estimando-se ter causado cerca de 4000 casos de COVID-19 (prevalência de 25\% na primeira semana de abril). ${ }^{3}$ Foi esta a primeira variante genética de relevo a ter um grande impacto em Portugal, numa altura onde ainda pouco se falava de variantes. Foi, no entanto, sem se saber na altura, a causa da cerca sanitária de Ovar e da primeira proibição de circulação entre concelhos. O exemplo mais notório do impacto da vigilância genética em termos de saúde pública e de decisão política está associado à identificação da emergência e disseminação da variante genética do Reino Unido (B.1.1.7) no nosso país. De facto, a perceção de que esta variante, com múltiplas introduções durante a última quinzena de dezembro, estava a duplicar a sua prevalência a cada semana em janeiro e estimava-se que num prazo de três semanas pudesse atingir $65 \%$ de prevalência, ${ }^{4}$ esteve na base da decisão do encerramento das escolas em janeiro de 2021.

Apesar da modesta taxa de mutação (cerca de duas mutações por mês) que o SARS-CoV-2 apresenta quando comparado com outros vírus com o mesmo tipo de material genético (RNA), o mesmo tem mostrado, no entanto, uma extraordinária capacidade de adaptação. Algumas das mutações que tem apresentado na proteína de superfície (Spike), a qual se liga ao recetor das nossas células e tem múltiplos domínios de reconhecimento por parte dos nossos anticorpos, têm-lhe permitido, por exemplo, ultrapassar a barreira de múltiplas espécies de mamíferos, potenciar a sua transmissão e diminuir a afinidade para com anticorpos neutralizantes. E é precisamente com base no aparecimento destas mutações que têm emergido as VOI (variant of interest) e as mais preocupantes VOC (variant of concern), assim definidas pelas autoridades de saúde mundiais. Apesar de não haver uma definição una por parte da Organização Mundial de Saúde (OMS), Centers for Disease Control and Prevention (CDC) e European Centre for Disease Prevention and Control (ECDC), este último organismo define VOC, ${ }^{5}$ em termos gerais, como uma variante com mutações com impacto fenotípico associado a: i) aumento na transmissibilidade; ii) aumento da virulência ou alteração no grau de severidade da doença; ou iii) diminuição na efetividade das medidas de saúde pública, dos testes de diagnóstico, das vacinas e da terapêutica. É neste cenário que se enquadra a já referida variante do Reino Unido (B.1.1.7), a variante da África do Sul (B.1.351), e a variante de Manaus (P.1), todas com epidemiologia muito relevante a partir do último trimestre de 2020, refletida pela sua disseminação mundial. Se, por um lado, a variante do Reino Unido parece não ter concorrência em termos de transmissão acrescida (atingindo já $90 \%$ de prevalência no mês de abril em Portugal), as outras duas partilham uma mutação que está associada à diminuição de ligação aos anticorpos neutralizantes de pessoas naturalmente infetadas ou vacinadas. Apesar disso, refira-se que os ensaios até agora feitos com estas variantes mostram que as vacinas testadas mantêm uma elevada eficácia em termos de proteção contra a doença grave. No entanto, algumas empresas farmacêuticas anunciaram estar já a proceder a alterações nas vacinas de acordo com as VOC circulantes. Mais recentemente, ganhou relevo epidemiológico a variante Indiana (B.1.617.2), a qual apresenta também mutações associadas à fuga ao sistema imunitário, tendo sido classificada como VOC pelo ECDC a 24 de maio de 2021.

Não devemos ficar surpresos com o cenário de emergência de VOC a que assistimos atualmente. De facto, ele é expectável tendo em conta os mais de 150 milhões de infetados e o mais de um bilião de vacinados até hoje ${ }^{1}$ dado que, perante uma população cada vez mais imunizada apenas os vírus com este tipo de mutações se poderão adaptar e disseminar. Além disso, a vacinação crescente das populações está a ser acompanhada por um processo de desconfinamento e de abertura gradual de fronteiras, o que se traduzirá pela inevitabilidade de introduções e circulação mundial de novas variantes. Talvez se entre assim num círculo vicioso em que novas variantes impliquem novas e/ou adaptadas vacinas, as quais, por sua vez, poderão estar na base da emergência de novas variantes.

A título de conclusão, que não restem dúvidas que o 'ping-pong' de introduções e circulação global das variantes genéticas vem ilustrar que dificilmente podemos garantir a saúde em portugueses isoladamente de uma saúde na Europa e no resto do mundo. Finalmente, perante a constatação inequívoca de que a 'genómica' do SARS-CoV-2 foi um dos volantes da pandemia, podemos afirmar que se deu início a uma nova era, na qual a sequenciação genómica dos agentes infeciosos e a saúde pública andarão de mão dada num processo de sinergia dinâmica em prol da saúde individual e coletiva.

\section{REFERÊNCIAS}

1. World Health Organization. who health emergency dashboard. [consultado 2021 maio 10]. Disponível em: https://covid19.who.int/.

2. Wu F, Zhao S, Yu B, Chen YM, Wang W, Song ZG, et al. A new coronavirus associated with human respiratory disease in China. Nature. 2020;579:265-9.

3. Borges V, Isidro J, Cortes-Martins H, Duarte S, Vieira L, Leite R, et al. Massive dissemination of a SARS-CoV-2 Spike Y839 variant in Portugal. Emerg Microbes Infect. 2020;9:2488-96.

4. Borges V, Sousa C, Menezes L, Gonçalves AM, Picão M, Almeida JP,

et al. Tracking SARS-CoV-2 lineage B.1.1.7 dissemination: insights from nationwide spike gene target failure (SGTF) and spike gene late detection (SGTL) data, Portugal, week 492020 to week 3 2021. Euro Surveill. 2021;26:2100131.

5. European Centre for Disease Prevention and Control. Guidance for representative and targeted genomic SARS-CoV-2 monitoring. [consultado 2021 maio 10]. Disponível em: https://www.ecdc.europa.eu/ en/publications-data/guidance-representative-and-targeted-genomicsars-cov-2-monitoring. 